\title{
The rhythm of healthy kidneys
}

\author{
Daniela Egli-Spichtig ${ }^{1} \cdot$ Carsten A. Wagner $^{2}$ (D)
}

Received: 27 June 2019 /Revised: 27 June 2019 / Accepted: 3 July 2019 /Published online: 12 July 2019

(C) Springer-Verlag GmbH Germany, part of Springer Nature 2019

Renal function in general as well as many essential body functions and systemic parameters undergo pronounced circadian fluctuations [8]. Among these systems is mineral homeostasis where the concentration of calcium and phosphate in blood and hormones such as parathyroid hormone (PTH), fibroblast growth factor 23 (FGF23), and $\alpha$-Klotho regulate mineral balance.

Chronic kidney disease (CKD) is a devastating disease affecting mineral balance and leading eventually to phosphate overload with excessively increased morbidity and mortality due to cardiovascular disease (CVD) [13, 14]. Elevated PTH, FGF23, and phosphate have been independently associated with cardiovascular disease in CKD and at least in the case of phosphate, evidence from experimental animal models and clinical studies is overwhelming to demonstrate a direct causal link between phosphate and mechanisms leading to CVD.

Disordered mineral balance in kidney disease starts very early. During acute kidney injury (AKI), FGF23 rises rapidly and massively [6, 2]. Similar in CKD, FGF23 rises very early and slowly when glomerular filtration rate (GFR) declines [11, $9,4]$. Also, $\alpha$-Klotho levels in kidney, circulation, and urine fall and this may even precede the rise in FGF23. Also, levels of calcitriol decrease progressively. Later, in the progress of $\mathrm{CKD}, \mathrm{PTH}$ increases and only in late stages also serum phosphate is elevated. At the same time, loss of circadian rhythms for plasma phosphate, calcium, PTH, and FGF23 ensues.

Neutralization of FGF23 with neutralizing antibodies has shown that FGF23 plays an important role in early kidney

This article is a comment to the original article https://doi.org/10.1007/ s00424-019-02291-2

Daniela Egli-Spichtig

Daniela.Egli-Spichtig@uzh.ch

Carsten A. Wagner

Wagnerca@access.uzh.ch

1 Institute of Physiology, University of Zurich, Winterthurerstrasse 190, CH-8057 Zurich, Switzerland

2 National Center of Competence in Research NCCR Kidney.CH, Zurich, Switzerland disease to protect against phosphate overload and CVD [12]. However, it has remained unclear what triggers the early rise of FGF23 as plasma phosphate levels tend to be rather low in early CKD. FGF23 is enzymatically degraded probably involving sortilin-like proteases; it may in part be cleared by renal excretion and both processes appear to be reduced in kidney disease. Moreover, we and others found that proinflammatory cytokines such as tumor necrosis factor (TNF), interleukin $1 \beta$ (Il-1 $\beta$ ), and Il-6 stimulate FGF23 production $[7,5,3]$.

In this issue of Pflügers Archiv, Nordholm and colleagues add another facet to this puzzling picture [10]. They analyze the circadian fluctuations of various circulating parameters of mineral homeostasis together with activin A in normal rats and rats with reduced kidney function consuming different diets with increasing phosphate content. Their results not only confirm the loss or changes in circadian rhythmicity of important players in mineral homeostasis but also show that activin A levels are increased in animals with reduced kidney function, further increased by high-phosphate intake, and that the circadian rhythm of activin A shows a reduced amplitude in CKD models.

\section{Why could this be of interest?}

Activin A is a glycoprotein that either alone or after forming heterodimers together with activin B acts as an endocrine factor. Initially, recognized as a positive regulator for folliclestimulating hormone (FSH) release, it has become clear that particularly activin A plays many more roles in normal physiology and disease processes (for review see reference [1]). Activin A belongs to the superfamily of transforming growth factor $\beta$ (TGF- $\beta$ ) and is signaling through ActRIIA/B receptors and Smads to alter transcription of target genes. Activin A and its receptors are widely expressed in many tissues including kidney where it is involved in branching morphogenesis and kidney repair, in the brain where it has neuron-protective functions, and in heart and the vascular system where it controls cardiac myogenesis and cardiac remodeling. 
In the kidney, activin $\mathrm{A}$ is produced by peritubular myofibroblasts activated during kidney disease and repair processes. It suppresses renal $\alpha$-Klotho levels which may be of importance as $\alpha$-Klotho is required for canonical FGF23 signaling and has been shown to exert protective effects on the kidney and cardiovascular structures and functions. Activin A stimulates proliferation of fibroblasts and induces fibrosis at the same time inhibiting tubular cell proliferation and differentiation.

Additional effects of activin A on skeletal muscle and bone may be important for our understanding of the mineral-bonedisorder in CKD patients (CKD-MBD). Activin A has negative effects on skeletal muscle recovery and proliferation. The effects of activin A on adult bone are controversial and activin A may have stimulatory effects on osteoblasts and bone mineralization as well as induce osteoclasts and reduce bone mineralization. Obviously, these processes are disturbed in CKDMBD and whether activin A signaling may contribute remains to be clarified. Some of the controversial effects may be explained by altered circadian rhythms of hormones like PTH or activin $A$ and the results reported by Nordholm and colleagues may promote further research in this direction.

The recognition of activin $\mathrm{A}$ as an additional factor produced by the injured kidney and acting on target organs involved in the pathogenesis of CKD-MBD makes this an interesting molecule not only for our understanding of the disease but also as a potential marker of disease progression or even as a novel target for interventions.

Funding information The work of the authors has been supported by the National Center of Competence in Research NCCR Kidney.CH, a Switzerland-wide research network funded by the Swiss National Science Foundation.

\section{References}

1. Bloise E, Ciarmela P, Dela Cruz C, Luisi S, Petraglia F, Reis FM (2019) Activin A in mammalian physiology. Physiol Rev 99:739780. https://doi.org/10.1152/physrev.00002.2018

2. Christov M, Waikar SS, Pereira RC, Havasi A, Leaf DE, Goltzman D, Pajevic PD, Wolf M, Juppner H (2013) Plasma FGF23 levels increase rapidly after acute kidney injury. Kidney Int 84:776-785. https://doi.org/10.1038/ki.2013.150

3. David V, Martin A, Isakova T, Spaulding C, Qi L, Ramirez V, Zumbrennen-Bullough KB, Sun CC, Lin HY, Babitt JL, Wolf M (2016) Inflammation and functional iron deficiency regulate fibroblast growth factor 23 production. Kidney Int 89:135-146. https:// doi.org/10.1038/ki.2015.290
4. Dhayat NA, Ackermann D, Pruijm M, Ponte B, Ehret G, Guessous I, Leichtle AB, Paccaud F, Mohaupt M, Fiedler GM, Devuyst O, Pechere-Bertschi A, Burnier M, Martin PY, Bochud M, Vogt B, Fuster DG (2016) Fibroblast growth factor 23 and markers of mineral metabolism in individuals with preserved renal function. Kidney Int 90:648-657. https://doi.org/10.1016/j.kint.2016.04.024

5. Durlacher-Betzer K, Hassan A, Levi R, Axelrod J, Silver J, NavehMany T (2018) Interleukin-6 contributes to the increase in fibroblast growth factor 23 expression in acute and chronic kidney disease. Kidney Int 94:315-325. https://doi.org/10.1016/j.kint.2018. 02.026

6. Egli-Spichtig D, Zhang MYH, Perwad F (2018) Fibroblast growth factor 23 expression is increased in multiple organs in mice with folic acid-induced acute kidney injury. Front Physiol 9:1494. https://doi.org/10.3389/fphys.2018.01494

7. Egli-Spichtig D., Imenez Silva PH, Glaudemans B., Gehring N., Bettoni C., Zhang M., Pastor Arroyo E., Schönenberger D., Rajski M., Hoogewijs D., Knauf F., Misselwitz B., Frey-Wagner I., Rogler G., Ackermann D., Ponte B., Pruijm M., Leichtle A., Fiedler G-M., Bochud M., Ballotta V., Hofmann S., Perwad F., Föller M., Lang F., Wenger R.H., Frew I., C.A. W (2019) Antibody mediated TNF neutralization decreases FGF23 levels in animal models of chronic kidney disease and non-renal inflammation. Kidney Int:in press

8. Firsov D, Bonny O (2018) Circadian rhythms and the kidney. Nat Rev Nephrol 14:626-635. https://doi.org/10.1038/s41581-0180048-9

9. Hu MC, Shiizaki K, Kuro-o M, Moe OW (2013) Fibroblast growth factor 23 and Klotho: physiology and pathophysiology of an endocrine network of mineral metabolism. Annu Rev Physiol 75:503533. https://doi.org/10.1146/annurev-physiol-030212-183727

10. Nordholm A., Egstrand S., Gravesen E., Mace M. L., Morevati M., Olgaard K., E. L (2019) Circadian rhythm of activin A and related parameters of mineral metabolism in normal and uremic rats. Pflügers Arch

11. Pavik I, Jaeger P, Ebner L, Wagner CA, Petzold K, Spichtig D, Poster D, Wuthrich RP, Russmann S, Serra AL (2013) Secreted Klotho and FGF23 in chronic kidney disease Stage 1 to 5: a sequence suggested from a cross-sectional study. Nephrol Dial Transplant 28:352-359. https://doi.org/10.1093/ndt/gfs460

12. Shalhoub V, Shatzen EM, Ward SC, Davis J, Stevens J, Bi V, Renshaw L, Hawkins N, Wang W, Chen C, Tsai MM, Cattley RC, Wronski TJ, Xia X, Li X, Henley C, Eschenberg M, Richards WG (2012) FGF23 neutralization improves chronic kidney disease-associated hyperparathyroidism yet increases mortality. J Clin Invest 122:2543-2553. https://doi.org/10.1172/JCI61405

13. Vervloet M (2019) Renal and extrarenal effects of fibroblast growth factor 23. Nat Rev Nephrol 15:109-120. https://doi.org/10.1038/ s41581-018-0087-2

14. Vervloet MG, Sezer S, Massy ZA, Johansson L, Cozzolino M, Fouque D, Disease-Mineral E-EWGoCK, Bone D, the European Renal Nutrition Working G (2017) The role of phosphate in kidney disease. Nat Rev Nephrol 13:27-38. https://doi.org/10.1038/ nrneph.2016.164

Publisher's note Springer Nature remains neutral with regard to jurisdictional claims in published maps and institutional affiliations. 